\title{
Prática docente: considerações sobre o planejamento das atividades pedagógicas
}

\section{Teaching practice: considerations about pedagogical activities planning}

\author{
Áurea Regina Guimarães Thomazi* \\ Thania Mara Teixeira Asinelli**
}

\begin{abstract}
RESUMO
Este artigo analisa um dos aspectos da prática docente que é o planejamento de atividades pedagógicas. Mais especificamente, trata de verificar como um grupo de professoras do ensino fundamental, das redes pública e privada, planeja as atividades de leitura que desenvolve em sala de aula. Busca-se estabelecer a relação entre o "individual" e o "coletivo" na elaboração de tal atividade, que está diretamente relacionada à construção e a implantação do currículo. A análise permitiu agrupar as práticas em três categorias de professoras: as que planejam de forma individual, sem qualquer apoio, outras que são independentes, por opção e, finalmente, as que planejam de forma coletiva, compartilhando com outros professores ou com a equipe técnica da instituição escolar.

Palavras-chave: planejamento; prática docente; construção do currículo; ensino fundamental; professores.
\end{abstract}

\begin{abstract}
This article analyzes one aspect of teaching practice which is pedagogic activities planning. More specifically, it approaches the way a group of elementary school teachers in both the private and public sectors plan reading activities to be developed in the classroom. This regards, above all, the prevalence of individual or collective planning, when performing such activity, which is straightly connected with the construction and

* Doutora em Ciências da Educação, Université Paris V. Professora Adjunta do Centro Universitário UNA. BH/MG. Professora da FAE/UEMG. E-mail: aureagt@gmail.com ** Doutora em Ciências da Educação, Université Paris V. Consultora em educação; Autora de livro didático/MEC. E-mail: thaniata@terra.com.br
\end{abstract}


implementation of the course syllabus. The analysis has led to grouping the teachers, according to their practices, into three categories: those who develop individual planning, without any support, those who have opted for being independent, and, finally, those who prefer collective planning, sharing with other teachers or the school technical team.

Keywords: planning; teaching practice; course syllabus construction; elementary school; teachers.

Ao se tratar de uma investigação sobre a maneira como os professores planejam, devemos perguntar se eles, de fato, elaboram um planejamento. Em que medida os professores pensam, refletem e preparam as atividades que irão desenvolver junto aos alunos? O planejamento existe apenas no nível das ideias ou é registrado? A direção e/ou a supervisão da escola impõem o que deverá ser realizado? E, nesse caso, estabelecem linhas gerais ou apresentam todas as ações detalhadamente?

A ação de planejar ultrapassa o planejamento propriamente dito, pois implica as relações de poder que se estabelecem entre os atores da instituição escolar. O planejamento ao mesmo tempo reflete e interfere nas relações entre: direção, supervisão, professores, além dos alunos e de suas famílias.

Apesar de se admitir que a dinâmica do contexto e do cotidiano escolares nem sempre permitem o acompanhamento rígido e inflexível do planejamento, tal ação, indiscutivelmente, organiza e sistematiza o trabalho pedagógico, evitando a improvisação. Assim, na perspectiva da previsão e da intencionalidade, evocamos Padilha (2001, p. 63):

Lembramos que realizar planos e planejamentos educacionais e escolares significa exercer uma atividade engajada, intencional, científica, de caráter político e ideológico e isento de neutralidade. Planejar, em sentido amplo, é um processo que visa dar respostas a um problema, através do estabelecimento de fins e meios que apontem para a sua superação, para atingir objetivos antes previstos, pensando e prevendo necessariamente $\mathrm{o}$ futuro, mas sem desconsiderar as condições do presente e as experiências do passado, levando-se em conta os contextos e os pressupostos filosófico, cultural, econômico e político de quem planeja e de com quem se planeja. 
A primeira questão que abordamos em uma pesquisa realizada junto a um grupo de professoras das redes, pública e privada do ensino fundamental ${ }^{1}$, sobre suas práticas de leitura em sala de aula, foi a respeito de como elas as planejavam. Interessamo-nos, na referida pesquisa, em conhecer os mecanismos de elaboração do currículo de leitura, partindo da etapa do planejamento, ou seja, verificar se os professores planejam e de que forma o fazem: coletiva ou individualmente, se discutem, se estudam e se refletem a própria prática; como se preparam e em que se apoiam, se elaboram um documento, um programa, enfim, buscamos compreender o que se passa durante as ações que antecedem a elaboração do currículo e sua aplicação efetiva junto aos alunos.

Convém primeiramente explicitar o sentido do termo "currículo" aqui adotado, o qual, segundo Forquin (1989, p. 213), serve a diversos usos, por se tratar de uma palavra de grande riqueza semântica. Assim, esclarecemos que se trata de "currículo escolar" definido como um

[...] percurso educacional, um conjunto de experiências de aprendizagens efetuadas por qualquer um sob o controle de uma instituição formal ao curso de um dado período. Por extensão, a noção designará menos um percurso efetivamente cumprido que um percurso prescrito por uma instituição escolar, quer dizer um programa, ou um conjunto de programas de aprendizagem organizadas em curso.

Apoiamo-nos ainda em Bernstein (1975, p. 263), que apresenta também uma importante contribuição à análise do currículo quando elabora uma construção conceitual em seu trabalho sobre código seriado e código integrado, estabelecendo as diferenças entre esses dois modelos na transmissão do "saber escolar". Ele explicita a relação entre o sistema de saber e o sistema de controle e de poder na sociedade, afirmando que "na forma de seleção, de classificação, de distribuição, de transmissão e de avaliação no sistema de ensino se inscrevem ao mesmo tempo a distribuição do poder e os princípios de controle próprios da sociedade". Assim, percebemos que o currículo é algo que deve ser "desvendado". Isso nos faz pensar que quando o currículo é concebido já existem forças e interesses diversos que refletem as relações de poder, os privilégios e o controle sobre certos grupos sociais. E o conflito de interesse permanece

1 A referida pesquisa foi realizada junto a 33 professoras de 13 escolas da rede de ensino de Belo Horizonte. Todas elas exercendo nas $3^{\mathrm{a}}$ e $4^{\mathrm{a}}$ séries do ensino fundamental, sendo cinco escolas da rede estadual, três da rede municipal e as outras cinco da rede privada. O nível sócio econômico das escolas bem como dos alunos é bastante diversificado. 
após a concepção do currículo, ou seja, durante a transmissão e avaliação dos programas desenvolvidos pelos professores na escola. Essa reflexão nos parece apropriada quando nos propomos a analisar as diferentes condições de construção do currículo, as diferentes participações dos professores, nas diversas escolas e as respectivas "relações de força" que aí se estabelecem.

É importante esclarecer que, na referida pesquisa, nos dedicamos a analisar ainda as práticas de leitura desenvolvidas pelas professoras entrevistadas. Entretanto, distinguimos neste estudo o currículo formal ou oficial do currículo declarado. O primeiro deles, o oficial, se refere ao currículo prescrito pela instituição escolar que pode ser elaborado para o professor, com a participação do mesmo, ou ainda por ele isoladamente, enquanto o segundo concerne às praticas pedagógicas "declaradas" pelas entrevistadas, que foram analisadas a partir de seus discursos ${ }^{2}$.

No presente artigo, entretanto, nos limitamos aos aspectos relativos ao currículo formal ou oficial, relatados pelas professoras entrevistadas na forma do que elas denominaram "planejamento". Interessamo-nos em conhecer como os professores preparam as atividades que irão desenvolver com os alunos, para em seguida analisarmos as concepções que fundamentam a seleção dessas mesmas atividades. Seguimos uma hipótese elaborada por Perrenoud (1994, p. 35), a respeito de como planejam os professores, quando ele admite parecer razoável a existência de "uma grande variação de um mestre a outro" e ao mesmo tempo "ligações bem estreitas entre o tipo de preparação e o tipo de pedagogia" adotados pelos professores.

Em uma primeira etapa, antes de entrevistarmos as professoras ${ }^{3}$, analisamos o currículo vigente, proposto pela Secretaria de Estado da Educação. Em seguida, durante as entrevistas, nos reportamos a essa proposta, no sentido de saber se havia alguma correspondência entre ela e os currículos planejados pelas professoras.

Partindo do pressuposto de que existe uma grande variedade na forma de planejar, entre os professores, acreditamos que "abordando uma lição, uma

2 Trata-se de um currículo intermediário entre o formal/oficial e o currículo real, aquele efetivamente praticado. Inspiramos-nos no trabalho de Favre e Perrenoud (1985, p. 67), em que os autores analisam as dificuldades de introduzir novas práticas pedagógicas, a partir dos discursos dos professores, ou seja, "através do discurso que os professores têm sobre as atividades que eles propõem aos alunos". Estes autores ressaltam ainda, que neste discurso "o ponto de vista é parcial porque trata-se de uma reconstrução da realidade" mas isso se justifica porque "compreender as práticas passa por uma parte não negligente de apreensão das significações dos atores".

3 Referimo-nos sempre às professoras, porque todas as entrevistadas pertencem ao sexo feminino. Utilizamos o termo no masculino quando nos referirmos à categoria de professores em geral. 
atividade, o professor se inspira sempre em um projeto, em um cenário, em um conjunto de regras ou de ações mais ou menos presentes em seu espírito" (PERRENOUD, 1994, p. 26).

No que concerne às questões postas sobre o planejamento ${ }^{4}$, destacamos aquelas de fundamental importância para esta pesquisa. Existe um planejamento das práticas pedagógicas? No caso da resposta positiva, qual o grau de envolvimento e de participação? Dedica-se um momento específico, no calendário escolar, para o planejamento das atividades constitutivas do currículo? Os professores têm autonomia ou devem se submeter às decisões dos outros "atores" (direção, pais, equipe pedagógica, supervisão), na construção do planejamento? As experiências e práticas dos professores estão contempladas na elaboração do planejamento ou este é apenas um instrumento institucional?

\section{A elaboração do currículo na escola: três situações}

A análise das entrevistas no que se refere à maneira de elaborar o planejamento, permitiu-nos classificar as declarações das professoras em três categorias. À primeira categoria chamamos de Individual, pois se refere às professoras que não receberam qualquer planejamento ou orientação da supervisora e que não têm a ocasião ou oportunidade de trocar ideias com os colegas. Elas elaboram o planejamento completamente "sozinhas". A segunda categoria foi classificada como Independente, pois se trata de um grupo que, embora receba as orientações da supervisão ou direção da escola, se nega a seguir o que lhe é imposto e elabora seu próprio planejamento. A terceira e última categoria denominamos Coletiva, e engloba as professoras que elaboram o planejamento em conjunto com colegas e contam com o apoio da supervisão e/ou direção da escola, mesmo que em um segundo momento cada uma elabore seu próprio plano individual para o cotidiano.

Embora não seja nosso objetivo, neste artigo, aprofundar a análise sobre as diferenças entre as redes de ensino, privada, municipal e estadual, cabe ressaltar que as duas primeiras categorias: Individual e Independente foram identificadas

4 Em relação à terminologia concernente aos preparativos das atividades pedagógicas como programa ou plano de ensino, ao lado dos autores citados, incluímos ainda a definição de Houaiss (2001, p. 2232), para o verbo planejar e o substantivo planejamento, respectivamente: "elaborar o plano"; "projetar"; "preparação de um trabalho de uma tarefa com o estabelecimento de métodos convenientes, planificação"; "determinação de um conjunto de procedimentos, de ações, [...] visando a realização de determinado projeto". 
apenas na rede pública (municipal e estadual), sendo que a terceira categoria Coletiva foi observada nas duas redes de ensino e, de forma mais acentuada, nas escolas da rede privada.

Além das distinções entre as três categorias, constatamos algumas nuances no interior de cada uma delas, que merecem ser citadas. Na primeira categoria, as professoras que elaboraram seu planejamento, sem apoio da supervisão ou de colegas da escola, buscaram orientações com professoras ou supervisoras de outras escolas, mas principalmente se basearam nos livros didáticos. Em uma das escolas da rede estadual, uma professora declarou que seu referencial era "o livro didático e a sua consciência...". Nessas escolas não há um espaço institucionalizado para a discussão da prática de ensino, para a troca de ideias e de experiências entre professores, enfim, não há uma reunião oficial com a finalidade de analisar e refletir sobre o planejamento. O depoimento de uma delas ilustra a informalidade com que trocam ideias:

Eu envio um bilhete para uma colega: "Marina, eu vou trabalhar com esse texto, o que você acha?" Ela me envia a resposta. É assim, por meio de bilhetes bem curtos trocados entre nós no corredor da escola. Mas, ter um tempo para discutir... para isso não há horário previsto, isso não é permitido na escola [...].

Nesses estabelecimentos, a supervisão e mesmo a direção se ocupam de outras questões, muitas vezes da esfera administrativa, deixando de lado o que se refere ao pedagógico.

Ao contrário dessa situação, as professoras "independentes" recebem a orientação da supervisora e as Diretrizes da Secretaria de Educação, mas insistem em elaborar seu próprio planejamento sem consultar os demais. Isso ocorre onde a supervisão se envolve com os aspectos pedagógicos, mas de forma pouco assertiva, ou seja, ela não se impõe, nem interfere na atuação dos professores. Assim, algumas das entrevistadas recebem as orientações da escola, além das Diretrizes da Secretaria de Educação, mas elaboram um planejamento em uma perspectiva própria, de forma a se distinguir das demais e das sugestões da supervisão, como declara uma delas: "Eu tento sair um pouco do tradicional. Mas não é fácil. Isso exige mais trabalho ainda. Eu sigo o mesmo planejamento que elaborei na outra escola onde trabalho como supervisora. Aqui eu sou a 'dona' da sala de aula e faço como eu quero. A supervisora é muito aberta...”.

Notamos que a diferença entre essas duas categorias não é grande. $\mathrm{Na}$ primeira, as professoras estão sozinhas porque são abandonadas pela supervisão 
enquanto na segunda, a opção de elaborar seu próprio plano, parte das próprias professoras. Embora exista, a supervisão é ausente ou quase nula e a escola não oferece um espaço ou um tempo no calendário escolar exclusivos para a troca de experiências, avaliação das práticas ou elaboração do planejamento.

Entretanto, em uma das escolas cujas professoras classificamos como "independentes" verificamos a existência de um "Projeto" de incentivo à leitura, do qual alguns professores foram convidados a participar com o objetivo de discutir e refletir as suas práticas pedagógicas de leitura. Ainda assim, havia certa resistência da parte de alguns, o que nos leva a pensar sobre um alerta de Perrenoud (1994, p. 33), a propósito da criação de espaços de trabalho comuns que poderiam favorecer uma melhor leitura e interpretação das experiências pedagógicas:

[...] os professores demonstram muita resistência em falar de suas práticas aos colegas. É preciso que haja relações de confiança que pressuponham ligações de amizade ou a sensação de fazer parte integrante de uma equipe pedagógica.

É preciso ressaltar que embora essas professoras não sigam um planejamento imposto pela escola, elas têm consciência de que precisam seguir certas diretrizes, como algumas declararam, "nem que seja o livro didático", de maneira que não fujam demasiadamente do que seria prescrito pela direção do estabelecimento escolar.

Constatamos assim, que nesta segunda categoria Independente, trata-se de profissionais que defendem o direito de ter certa autonomia em relação à supervisão e querem demonstrar que são capazes de se "virar" sem apoio de ninguém. A declaração de uma delas sobre a não utilização de fichas de interpretação de texto "prontas para usar", que são incluídas em certos livros, é um exemplo de busca de autonomia. Essa professora relata várias de suas estratégias para estimular os alunos a lerem, mas ela jamais utiliza esse tipo de ficha, mesmo sabendo que outras adotam: "Mesmo a supervisora é favorável à utilização dessas fichas, mas a mim ela não diz nada, porque ela sabe que eu não aprovo". Nesse caso, a situação é favorável a esta professora, pois, caso a supervisão fosse mais atuante, ou mesmo mais autoritária poderiam ocorrer conflitos devidos à divergência de pontos de vista. A referida professora também é supervisora em outra escola, com 18 anos de experiência no magistério, além de uma formação superior em pedagogia e cursos de formação contínua. Ela se julga, portanto, segura de sua prática, e, de certa forma, impõe sua autonomia. 
Com relação a esse aspecto, Tochon $(1989$, p. 86), em um artigo sobre planejamento de aulas trata da autonomia do professor e cita Hashweh, que afirma: "[...] quanto mais o professor é competente mais ele toma a liberdade na utilização de manuais escolares". Nesse sentido, podemos pensar que certa competência favorece a autonomia do professor em relação ao planejamento, em relação à supervisão ou às outras imposições da instituição escolar.

Um outro depoimento ainda na categoria Independente aborda uma situação em que a professora não tem curso superior e apesar dos treze anos de magistério nunca havia lecionado para a $3^{\mathrm{a}}$ série e não dominava o conteúdo deste nível de ensino, que lhe foi passado pela supervisão:

Eu fiz pesquisas, fui ao IBGE, fiz levantamentos sobre a população [...] Eles riram muito de mim e disseram que não valia a pena. Mas como eu posso ensinar algo que não sei? [...] Eu fui ao Serviço de Meteorologia, na Secretaria do Meio Ambiente [...] e trouxe cartazes e mapas. Isso me beneficiou muito, aprendi muitas coisas [...].

Percebemos, portanto, que a terceira categoria denominada Coletiva se distingue das duas anteriores. Como foi mencionado anteriormente, ela compreende professoras das redes estadual, municipal e privada com destaque para esta última, além de englobar o maior número de entrevistadas de nossa pesquisa ${ }^{5}$. O que é interessante observar nesta categoria, apesar das diferenças ou nuances existentes é que todas essas professoras declararam ter reuniões de planejamento periodicamente, durante o semestre, com o conjunto de professores e a supervisão ou com colegas do mesmo nível de ensino. Outro ponto comum é o fato de que o planejamento anual parte de uma avaliação da prática realizada, o que acontece em reuniões no final ou no início do ano. Desta forma, as experiências bem sucedidas são retomadas, enquanto outras consideradas "fracassadas" são deixadas de lado, além da introdução de novas atividades, como testemunha uma professora da rede municipal: "Nós elaboramos nosso currículo com algumas práticas que são satisfatórias e já constatamos que dão resultados”. Uma outra professora da rede pública, afirma: “[...] no início do ano, nós estabelecemos os planejamentos, primeiro o anual depois o mensal [...] nós nos reunimos a cada semana e fazemos o planejamento semanal, discutimos, fazemos uma seleção

5 As professoras classificadas na categoria das que planejam de forma coletiva somam vinte de um total de trinta e duas entrevistadas, sendo duas da rede estadual, cinco da rede municipal e treze da rede privada. 
de textos, vemos os resultados na sala de aula [...]". E ainda, um depoimento de uma professora da escola privada: "No final do ano nós nos reunimos por nível de ensino e fazemos a avaliação do planejamento do ano que terminou, porque ele é a nossa referência. Nós analisamos o que funcionou ou não, o que deve ser mantido e o que é preciso modificar [...]".

O que difere nestas escolas é que, além do planejamento propriamente dito das atividades a serem desenvolvidas, o que compreende não apenas o conteúdo, mas a metodologia e o sistema de avaliação, em algumas delas os professores têm ainda a oportunidade de alguns encontros exclusivos para estudo e reflexão de textos teóricos que servem de suporte à prática pedagógica e ao próprio planejamento. Esse espaço de reflexão e socialização das experiências garante maior segurança ao professor que se sente mais à vontade e mais consciente de sua prática. Os professores trabalham com um espírito de equipe e, ao mesmo tempo, têm certa liberdade e autonomia dentro da sala de aula, conforme declarou uma professora da rede municipal:

Em nosso país, é demais! O professor de ensino fundamental é o todo poderoso dentro da sala de aula, o Deus, com o poder e a autoridade máximos. Eu penso que é preciso dividir as responsabilidades [...] Então, estou feliz por trabalhar nesta escola porque aqui as colegas concordam em dividir os ganhos e os custos.

\section{A dinâmica da construção do currículo: a instituição e o indivíduo}

Diante dessas considerações, um aspecto merece ser sublinhado: os determinantes pessoais da prática de planejamento de cada profissional guardam uma relação de acordo com o estabelecimento escolar: público ou privado. Portanto, não podemos ignorar a influência do estabelecimento onde o professor atua.

Neste sentido, a construção do currículo ${ }^{6}$ percorre diferentes fases nas quais podem predominar os aspectos individuais ou institucionais. Procuramos verificar a dinâmica da construção social do currículo, considerando as práticas

6 A expressão "construção do currículo" aqui, refere-se não apenas à escolha de conteúdos, mas passa pela prática desenvolvida junto aos alunos e inclui até mesmo a convicção do professor em relação ao sucesso deste currículo. 
dos professores, tal como Plaisance (1988, p. 344) esclarece: “[...] definir as práticas não como práticas ditadas por esta ou aquela instituição, mas como práticas sobre as quais se exerce ao mesmo tempo as imposições das instituições e as iniciativas dos indivíduos ou dos grupos".

No que se refere à elaboração do currículo ou planejamento, percebemos que em determinado momento a instituição, a direção, a supervisão e o trabalho em equipe prevalecem sobre a criação individual. Os planejamentos elaborados em equipe, nos casos aqui analisados, submetem-se à influência da instituição, na medida em que a direção ou a supervisão dele participam. Ao mesmo tempo, guardam a marca dos professores, pois se trata de um espaço onde eles podem incrementar suas práticas (conteúdos, metodologias, etc.) e trocar experiências. No momento em que o planejamento passa aos detalhes do cotidiano e, sobretudo, quando ele é dirigido à sala de aula é possível atribuir maior peso aos aspectos individuais dos professores.

Constatamos ainda que, mesmo as professoras que não elaboram o planejamento de forma coletiva ou em equipe, procuram referências nos manuais escolares e em outros estabelecimentos, ou seja, elas buscam apoio em instâncias institucionais e escolares.

Entretanto, verificamos que se pode atribuir um peso maior à iniciativa dos professores em algumas situações, por exemplo: em um mesmo estabelecimento duas professoras do mesmo nível possuem condutas bem diferentes, uma atrelada à supervisão e uma outra bastante independente.

Impõe-se assim, alguns questionamentos sobre o peso da instituição escolar e dos professores: qual deles teria a atuação mais considerável? $\mathrm{Na}$ ausência de um apoio pedagógico, de uma direção mais atuante, de uma equipe de trabalho ou de discussões, o professor teria maior liberdade para construir o planejamento e o currículo? Tal situação levaria os professores a uma maior autonomia?

O peso da instituição assim como a influência do currículo oficial ${ }^{7}$ seriam então mais ou menos importantes, na elaboração de cada currículo, segundo as condições objetivas que são oferecidas pelas diferentes escolas, da rede estadual, municipal ou privada, sem, no entanto, nos esquecermos que há diferenças entre as escolas de uma mesma rede.

7 Lembramos que consideramos aqui como currículo oficial, as diretrizes da Secretaria de Estado da Educação de Minas Gerais, a saber: Conteúdos Básicos - Português, de 1994. 


\section{A importância do planejamento para a implantação e o desenvol- vimento do currículo}

É importante revelar que a questão sobre o planejamento do currículo não pareceu importante para nossas entrevistadas, salvo quando se referia à existência de grupos de estudo, trocas de experiências entre professores e reuniões de discussões. Frequentemente, as professoras se referiram ao planejamento como algo bem simples que elas têm sempre "à mão", e que não apresenta "mistério" ou complexidade.

Parece-nos que o currículo elaborado individual ou coletivamente, já foi interiorizado pelos professores, que já o conhecem "de cor". É a partir desse conhecimento e das linhas gerais desse currículo que são elaborados os planejamentos anuais, mensais e diários. É então, na sala de aula, no momento da implantação do currículo, que iremos encontrar as iniciativas, a criatividade, as estratégias dos professores, sem, contudo, ignorar as imposições da instituição ${ }^{8}$.

Em nossa pesquisa nos dedicamos a outros aspectos relacionados ao planejamento e implementação das práticas de leitura das professoras entrevistadas, como o perfil de cada uma delas, no que concerne sua experiência, formação e suas práticas de leituras ${ }^{9}$. No entanto, dada a finalidade deste artigo, nos limitamos à verificação de que a maior parte de nossas entrevistadas possui um planejamento das atividades que serão desenvolvidas ao longo do ano, o qual contém as diretrizes e as sugestões de atividades. Elas se apoiam em um especialista (supervisão ou coordenação) e, em geral, trocam ideias com seus pares. Este planejamento possui uma flexibilidade que permite que as professoras, em sua autonomia, lhe imprimam algumas alterações, ao mesmo tempo em que elas se sentem seguras pelo fato de terem um apoio institucional e uma base sobre a qual possam criar.

Em escolas onde há grupos de estudo e trocas de experiências entre professores, ocorre certa legitimação das práticas pedagógicas e, nos casos aqui analisados não constatamos a existência de conflitos em relação ao conteúdo ou

8 As imposições neste caso são as exigências e as diretrizes que a direção da escola institui, mas também as condições de trabalho que ela oferece aos professores. Em outras palavras, todas as condições do ambiente institucional que fazem pressão sobre os professores e os obrigam, às vezes, a aceitá-las ou, ao contrário, optar por suas próprias iniciativas.

9 Analisamos entre outros aspectos o que chamamos de percurso biográfico do leitor, com base nos estudos de Peroni (1995), e Bahoul (1988), o que inclui o despertar do interesse pela leitura, além das leituras na infância, na juventude e práticas atuais. 
às metodologias propostas. Porém, se há conflitos na construção do currículo, as professoras se expressam, sobretudo, no momento da implementação, referindose a aspectos tais como: a escassez ou a qualidade dos livros, as condições objetivas de trabalho, os salários. Feita a ressalva de que nossa amostra não se pretende representativa de seu conjunto, constatamos uma unanimidade da parte das professoras na apreciação das reuniões de planejamento, sendo que aquelas que não têm essa oportunidade desejam-na e a reivindicam.

\section{O currículo: uma construção social}

Considerando os diversos atores ${ }^{10}$ presentes na atividade de planejamento e de elaboração do currículo, procuramos compreender essa prática sob a luz da teoria da construção social da realidade, que se "realiza em três momentos que não devem ser vistos como uma seqüência temporal, mas como uma dialética" (VAN HAECHT, 1990, p. 112). Esses três momentos de exteriorização, de objetivação e de interiorização estão presentes no processo de elaboração do currículo, na medida em que o trabalho, por ser coletivo, exige uma objetivação por parte da equipe de professores que exteriorizam suas práticas e ao mesmo tempo, pelo professor que, individualmente, interioriza o que é elaborado na construção coletiva, ou nas palavras de Berger e Luckmann (1966, p. 94): “O conhecimento sobre a sociedade é então uma realização nos dois sentidos do termo, primeiramente de uma apreensão da realidade social objetivada, e em seguida de uma produção desta realidade".

A propósito da exteriorização, Van Haecht (1990, p. 113), explica: “A atividade humana de construção do mundo é uma produção coletiva: a sociedade definida como esta parte da cultura que estrutura as relações incessantes do homem com seus semelhantes". Assim, percebemos no nível da análise micro sociológica de elaboração do currículo na escola, este mesmo processo concernente não só à prática do grupo das professoras classificadas na categoria Coletiva, mas também nas categorias Individual e Independente. Constatamos o que Berger e Luckmann (1966, p. 143) afirmam: "Como o homem se exterioriza, ele constrói o mundo no qual se exterioriza. No processo de exteriorização ele projeta suas próprias significações na realidade".

Ao mesmo tempo,

10 Professores, supervisão, direção, editoras, pais, Secretarias de Estado, ente outros. 
a objetivação pressupõe o fato de que as criações humanas ou produtos exteriorizados se beneficiam de uma autonomia relativa [...]. A idéia de objetividade da cultura se exprime sob duas formas: aquela de uma objetividade que se impõe ao homem como conjunto de objetos do mundo real, tendo uma existência própria além da sua consciência e aquela de uma experiência coletiva, remetendo a objetos susceptíveis de serem partilhados com os outros - a cultura está lá para todos - independente das construções da consciência subjetiva do indivíduo isolado (VAN HAECHT, 1990, p. 113).

Notamos então, que o currículo formal, oficial ou aquele elaborado na escola se apresenta algumas vezes como autônomo, com uma existência própria, independente dos professores. Ao mesmo tempo, ele é reconhecido como uma produção coletiva da qual todos usufruem. O currículo oficial e/ou formal considerados como realidades objetivas do mundo institucional são "exteriores" ao professor, "persistindo em sua realidade", quer ele "queira ou não" (BERGER; LUCKMANN, 1996, p. 86). Neste sentido, os professores das três categorias: Coletiva, Individual e Independente percebem o currículo como algo relativamente autônomo, mas que é compartilhado por todos.

Finalmente, o momento da interiorização se caracteriza "pelo momento da reabsorção do mundo objetivo no interior da consciência, de maneira que as estruturas deste mundo objetivo determinam as estruturas subjetivas desta consciência" (VAN HAECHT, 1990, p. 113). Este momento aparece quando o professor interioriza o planejamento e coloca em prática um currículo que ele já conhece, o que também se percebe em relação às decisões que pertencem preferencialmente ao currículo oculto, como explica Perrenoud (1994, p. 2). Esse tipo de decisão,

[...] parece referir-se preferencialmente ao automatismo da rotina do que a uma estratégia reflexiva. Em situação de urgência, mobilizamos certamente fragmentos de representações e de conhecimentos; racionalizamos, mesmo que pouco. Mas nos apoiamos em grande parte sobre esquemas de ação, de percepção e de decisão parcialmente inconscientes. Daí, a impressão de muitos professores de ensinarem com base no que "eles são": em sua personalidade ou em sua experiência.

Entretanto, as professoras de nossa amostra, que participaram de discussões e planejamentos coletivos, parecem ter maior facilidade para interiorizar 
o que foi elaborado e construído coletivamente. As que compõem as outras duas categorias: Individual e Independente, também interiorizam o conteúdo do currículo formal, sem, no entanto, passar pela etapa do trabalho coletivo. Neste último caso, a interiorização é possivelmente devida à experiência de leitura e ao conhecimento das normas e diretrizes dos currículos que estão à disposição dos professores, incluindo o currículo oficial.

Berger e Luckmann (1996, p. 179) explicam ainda, que somente quando o indivíduo alcança certo "grau de interiorização" é que ele "se torna um membro da sociedade”. É possível que para os professores, em muitos casos, seja difícil distinguir o que é construído por eles próprios e o que é interiorizado a partir de uma construção coletiva da qual ele tenha participado, pois muitas vezes o currículo pode lhes parecer apenas "como dados exteriores" (VAN HAECHT, 1990, p. 113). É, portanto, no movimento dialético entre estes três momentos, de exteriorização, de objetivação e de interiorização que os professores planejam suas práticas pedagógicas de leitura e constroem o currículo escolar.

\section{REFERÊNCIAS}

BAHOUL, J. Lectures précaires, étude sociologique sur les faibles lecteurs. Paris: Service des estudes et de la recherche, BPI Centre George Pompidou, 1988.

BERGER, P.; LUCKMANN, T. La construction sociale de la réalité. 10. ed. Paris: Armand Colin, 1996. (1. edition en anglais, 1966).

BERNSTEIN, B. Langage et classes sociales. Codes sócio-linguistiques et contrôle social. Paris: Editions de Minuit, 1975.

FAVRE, B.; PERRENOUD, P. Organisation du Curriculum et Différentiation de l'Enseignement. In: PLAISANCE, E. (Dir.). L'Echec Scolaire. Nouveaux Débats, Nouvelles Approaches Sociologiques. Actes de Colloque franco-suisse 9-12 jan. 1884. Paris: CNRS, 1985.

FORQUIN, J. C. Ecole et Culture. Le point de vue des sociologues britanniques. Bruxelles: De Boeck Université, 1989.

HOUAISS (Ed.). Dicionário Houaiss da Língua Portuguesa. Rio de Janeiro: Editora Objetiva, 2001.

PADILHA, P. R. Planejamento Dialógico: Como construir o projeto políticopedagógico da escola. São Paulo: Ed. Cortez, 2001. 
PERONI, M. Histoires de Lire. 2. ed. Paris: BPI Centre Georges Pompidou, 1995.

PERRENOUD, P. La Formation des Enseignants entre théorie et pratique. Paris: L'Harmattan, 1994. (Savoir et Formationa).

PLAISANCE, E. "Sur l'utilisation des notions d'acteur de jeu et de stratégie". In: PERRENOUD, P.; MONTANDON, C. Qui maîtrise l'école? Lausanne: Réalités Sociales, 1988.

SECRETARIA DE ESTADO DA EDUCAÇÃO DE MINAS GERAIS. Conteúdos Básicos - Português, Belo Horizonte, 1994.

TOCHON, F. “A quoi pensent les enseignants quand ils planifient leurs cours?”. Revue Française de Pédagogie, n. 86, jan./fev./mar. 1989.

VAN HAECHT, A. L'Ecole à l'euprevue de la sociologie. Bruxelles: De Boeck, 1990. (Ouvertures Sociologiques).

Texto recebido em 16 de outubro de 2007.

Texto aprovado em 13 de abril de 2009. 